\title{
Safety of parathyroidectomy in older vs. younger patients with primary hyperparathyroidism
}

\author{
Marlena Mueller ${ }^{1,2}$, Fahim Ebrahimi ${ }^{3,4}$, Emanuel Christ ${ }^{3}$, Christian Andreas Nebiker ${ }^{5}$, Philipp Schuetz ${ }^{1,2,6}$, \\ Beat Mueller ${ }^{1,2,6}$ and Alexander Kutz ${ }^{1,2}$ \\ ${ }^{1}$ Division of Endocrinology, Diabetes, and Metabolism, University Department of Medicine, Kantonsspital Aarau AG, Aarau, Switzerland \\ ${ }^{2}$ Division of General and Emergency Medicine, University Department of Medicine, Kantonsspital Aarau AG, Aarau, Switzerland \\ ${ }^{3}$ Division of Endocrinology, Diabetes, and Metabolism, University Hospital Basel, Basel, Switzerland \\ ${ }^{4}$ University Center for Gastrointestinal and Liver Diseases, St. Clara Hospital and University Hospital, Basel, Switzerland \\ ${ }^{5}$ Department of Surgery, Kantonsspital Aarau AG, Aarau, Switzerland \\ ${ }^{6}$ Faculty of Medicine, University Hospital Basel, Basel, Switzerland
}

Correspondence should be addressed to M Mueller: marlenamueller@gmx.ch

\begin{abstract}
Background: Primary hyperparathyroidism is a prevalent endocrinopathy for which surgery is the only curative option. Parathyroidectomy is primarily recommended in younger and symptomatic patients, while there are still concerns regarding surgical complications in older patients. We therefore assessed the association of age with surgical outcomes in patients undergoing parathyroidectomy in a large population in Switzerland.

Methods: Population-based cohort study of adult patients with primary hyperparathyroidism undergoing parathyroidectomy in Switzerland between 2012 and 2018. The cohort was divided into four age groups ( $<50$ years, 50-64 years, 65-74 years, $\geq 75$ years). The primary outcome was a composite of in-hospital postoperative complications. Secondary outcomes were intensive care unit (ICU) admission, unplanned 30-day-readmission, and prolonged length of hospital stay.

Results: We studied 2642 patients with a median (IQR) age of 62 (53-71) years. Overall, 111 patients had complications including surgical re-intervention, hypocalcemia, and vocal cord paresis. As compared to $<50$ year-old patients, older patients had no increased risk for in-hospital complications after surgery (50-64 years: odds ratio (OR): 0.51 ( $95 \% \mathrm{Cl}, 0.28$ to 0.92$) ; 65-74$ years: OR: 0.72 (95\% Cl, 0.39 to 1.33$) ; \geq 75$ years: OR: $1.03(95 \% \mathrm{Cl}, 0.54$ to 1.95$)$, respectively. There was also no association of age and rates of ICU-admission and unplanned 30-day-readmission, but oldest patients had longer hospital stays (OR: $2.38(95 \% \mathrm{Cl}, 1.57$ to 3.60$)$ ).

Conclusion: $\geq 50$ year-old patients undergoing parathyroidectomy had comparable risk of in-hospital complications as compared with younger ones. These data support parathyroidectomy in even older patients with primary hyperparathyroidism as performed in clinical routine.
\end{abstract}

Key Words
- age
- older patients
- parathyroidectomy
- primary
hyperparathyroidism
- postoperative
complications
- outcome

Endocrine Connections (2021) 10, 1273-1282

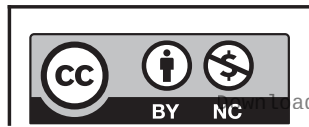

This work is licensed under a Creative Commons Attribution-NonCommercial 4.0 International License. ded from Bioscientifica.com at 04/26/2023 09:40:56AM 


\section{Introduction}

Primary hyperparathyroidism (pHPT) is an increasingly prevalent endocrinopathy, predominantly affecting elderly women $(1,2)$. Incidence rates increase with age, peaking in age-groups above 60 years, and varying with regard to sex and race $(2,3,4,5)$.

Parathyroidectomy (PTX) is the only known curative treatment for pHPT. Previous studies found a steady rise in PTXs performed during the past decades $(5,6)$, while a study from the US still reported undertreatment of PTX in older patients with pHPT (7). PTX should be performed in patients with symptomatic pHPT (8). Importantly, the vast majority of diagnosed cases in western countries are asymptomatic (9), thus not presenting with clinically manifest renal or skeletal symptoms (10).

According to the 'Fourth International Guidelines for the Management of Asymptomatic pHPT' (11), PTX is recommended if any of the following conditions are met, mainly indicating a higher risk of progression (10): Age $<50$ years, serum calcium $>0.25 \mathrm{mmol} / \mathrm{L}$ above the upper limit of normal, decreased bone mineral density in dual-energy $\mathrm{x}$-ray absorptiometry (T-score $<-2.5$ at lumbar spine, total hip, femoral neck, or distal 1/3 radius), vertebral fractures on imaging, a creatinine clearance $<60$ $\mathrm{mL} / \mathrm{min}$, 24-h urine calcium $>10 \mathrm{mmol} /$ day, or increased risk of nephrolithiasis/nephrocalcinosis by biochemical analysis or on imaging.

However, in clinical practice the decision to perform parathyroidectomy has been increasing, and PTX is frequently recommended to patients who do not meet the stringent criteria. Alternatively, pharmacological treatment with modulators of the calcium-sensing receptor is available, however, less cost-effective (12). They are usually not recommended as a first-choice option (8), especially since osteoporosis is not treated by calcimimetics $(13,14)$.

'The American Association of Endocrine Surgeons Guidelines for Definitive Management of Primary Hyperparathyroidism' reflects this development, recommending PTX to patients with neurocognitive and/or neuropsychiatric symptoms that are attributable to pHPT (15). In this context, it is conceivable that in an aging population neurocognitive and neuropsychiatric symptoms are frequent and may be aggravated by a concomitant pHPT.

Against this background and in line with a higher patient exposure to parathyroidectomies, the awareness on postoperative outcomes in older patients with pHPT is paramount.
Previous studies have reported conflicting findings concerning PTX-safety in elderly patients $(16,17,18,19$, $20,21,22,23,24,25$ ).

Hence, the purpose of this study was to evaluate the association of four different age categories with in-hospital postoperative complications among a large populationbased cohort with pHPT as surgically treated in the Swiss clinical routine.

\section{Materials and methods}

\section{Study design and data sources}

We conducted a nationwide population-based cohort study using administrative claims data ('Medizinstatistik') provided by the Federal Statistical Office in Switzerland from January 2012 to December 2018. The database contains longitudinal, individual-level data on in-hospital health care use, inpatient diagnoses, diagnostic tests, and procedures (https://www.bfs.admin.ch/bfs/de/home/ statistiken/gesundheit/erhebungen/ms.html, accessed January 03, 2021). It includes all Swiss inpatient discharge records from acute care-, general-, and specialty hospitals, excluding hospital units of postacute care institutions, regardless of payer, and thus creating a near complete sample of hospitalizations in Switzerland. Each hospitalization was identified uniquely so that re-hospitalizations could be tracked (https://www.swissdrg.org/application/ files/4714/8111/3146/160620_SwissDRG_Falldefinitionen_ v5.pdf, accessed July 16, 2020). All covariates were assessed during index hospitalization. The database included information such as place of residence, hospital teaching level, date of hospitalization, length of hospital stay (LOS), admission age, and admission diagnosis. Medical diagnoses were coded using the International Classification of Disease version 10, German Modification (ICD-10 GM) codes. Procedures were based on 'Swiss Classification of Operation' (CHOP) codes (26). The institutional review board of Northwestern Switzerland (AG/SO 2009/074 and EKNZ BASEC PB_2017-00449) approved this cohort study and waived the requirement of participant informed consent, as the data were deidentified. This study followed the Strengthening the Reporting of Observational Studies in Epidemiology (STROBE) reporting guideline (27).

\section{Participants}

To qualify for inclusion, hospitalized adult ( $\geq 18$ years) patients must have had a principal discharge record

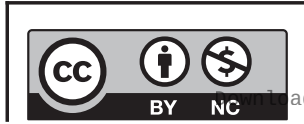

This work is licensed under a Creative Commons Attribution-NonCommercial 4.0 International License. ded from Bioscientifica.com at 04/26/2023 09:40:56AM 
featuring a procedure according to the CHOP-codes for parathyroidectomy (CHOP-codes shown in Fig. 1). Cases where the procedure parathyroidectomy was not classified as 'main treatment' were only included if no further surgery or major intervention was coded.

CHOP, 'Swiss classification of Operation' codes; ICD10-GM, International Classification of Disease version 10, German modification codes.

In the case that a single patient underwent more than one parathyroidectomy, only the primary procedure was included, thus including only one case per patient.

Further, all eligible patients required a diagnosis of pHPT to be included. Cases with pHPT were identified by applying ICD-10-GM codes of E21.0 (primary hyperparathyroidism) and/or D35.1 (benign neoplasm of the parathyroid gland).

To increase specificity of our cohort and to allow for better comparison between the patient subgroups, we excluded cases with CHOP-codes for parathyroidectomy by sternotomy, thoracoscopy or mediastinoscopy, procedures with concurrent thyroidectomy, thymectomy or neck dissection, and re-explorations (CHOP-codes shown in Fig. 1).

To address potential cases of tertiary hyperparathyroidism, we excluded cases with severe or end-stage kidney disease, kidney transplantation, and autosomal-dominant polycystic kidney disease (codes shown in Fig. 1).

To further increase comparability, we excluded patients with malignant neoplasms (thyroid gland, parathyroid glands, and lymph nodes), carcinoma in situ (thyroid gland, other endocrine glands), and neoplasms of uncertain dignity and patients with calcitonin hypersecretion (ICD10-codes shown in Fig. 1).

\section{Exposure}

The exposure of interest was patient's age. To assess the association of increasing age with primary and secondary outcomes of interest, we divided the cohort into four age-groups ( $<50$ years, 50-64 years, 65-74 years, and $\geq 75$ years, respectively). The group with patients $<50$ years was defined as reference group.

\section{Outcomes}

The primary outcome of in-hospital postoperative complications was a composite of the following ICD-10GM-based diagnoses: hypocalcemia (E20, E89.2, R25.2, and R25.3), vocal cord paresis and recurrent nerve paresis
(J38.00, J38.01, J38.02, J38.03, and G52.2), bleeding and neck hematoma (T81.0, CHOP: 39.98, 06.02), hemorrhagic shock or acute bleeding anemia (T81.1, D62), tracheal or airways injury (J95, J95.5, J95.81, S11.01, and S11.02), postoperative infection (T81.4, L02.1), sepsis (A40, A41, and R57.2), surgical re-intervention (CHOP: 00.99.10), and other postoperative complications (S04.8, S04.9, T81, T81.2, T81.3, T81.5, T81.6, T81.7, T81.8, T81.9, T88.8, and T88.9). Secondary outcomes included unplanned all-cause 30-day readmission, intensive care unit (ICU) admission, and a prolonged LOS of $>3$ days. To determine the cause of readmission, type of admission (emergency vs planned admission), primary and secondary diagnoses as well as coded treatments of each readmission were reviewed by two independent authors. Unplanned 30-day readmissions were finally categorized in 'parathyroidectomy-related' and 'parathyroidectomy-unrelated'.

\section{Statistical analysis}

Descriptive statistics were used to compare the four agegroups. Estimates of the effect size and corresponding 95\% CI were determined using linear and logistic regression, as appropriate. Multivariable regression analyses were adjusted for sex, patient nationality, Charlson comorbidity index, comorbidities (diabetes mellitus, neoplasms, cardiovascular diseases, coronary artery disease, congestive heart failure, high blood pressure, chronic obstructive pulmonary disease, renal insufficiency, and vitamin $\mathrm{D}$ deficiency), the presence of an end-organ sequelae associated with pHPT (osteoporosis, urolithiasis, and/or renal insufficiency), hospital size and teaching level, date and type of admission, and insurance status.

We performed sensitivity analyses to assess potential effect modification through the presence of a symptomatic pHPT (osteoporosis, urolithiasis and/or renal insufficiency).

Statistical significance was indicated by an alpha level of 5\%. All $P$-values were two-sided. Statistical analyses were performed using Stata 15.1 (StataCorp. 2015. College Station, TX, USA: StataCorp LP).

\section{Results}

\section{Index hospitalizations}

From January 2012 to December 2018, we included 2642 patients undergoing parathyroidectomy (Fig. 1). In the study, 673 (25.5\%) out of 2642 patients underwent 'total parathyroidectomy'. The proportion of the different

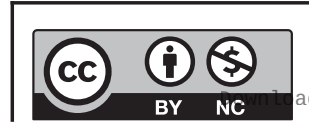




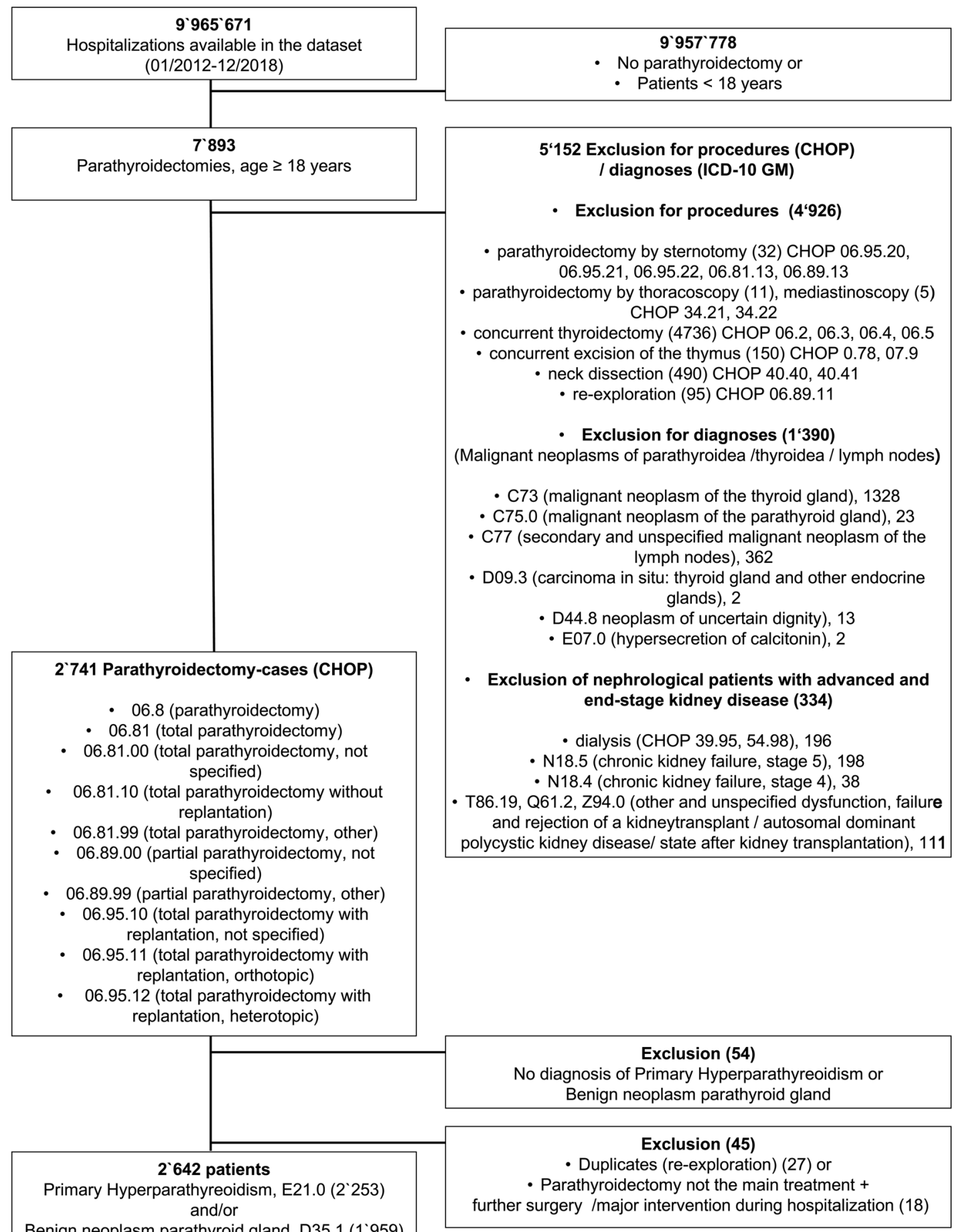

Figure 1

Study flowchart.

https://ec.bioscientifica.com

https://doi.org/10.1530/EC-21-0363 (c) 2021 The authors Published by Bioscientifica Ltd

1570 patients: E21.0 and D35.1

- 683 patients only E21.0

- 389 patients only D35.1 
procedures ('partial' vs 'total' parathyroidectomies) was balanced across all age groups, with $24.9 \%$ of total parathyroidectomies performed in the reference group and $27.6 \%, 24 \%$, and $23.6 \%$ of total parathyroidectomies in the age groups 50-64 years, 65-74 years and $>75$ years, respectively. A total of 474 patients were $<50$ years, 1012 aged between 50 and 64 years, 716 between 65 and 74 years, and 440 were $\geq 75$ years. A total of $73.3 \%$ of patients undergoing parathyroidectomy were female. Over the study period, the number of parathyroidectomies continuously increased, ranging from 312 in 2012 to 490 in 2018 (1.57fold increase). Older patients had a higher burden of comorbidities such as diabetes mellitus, heart failure, high blood pressure, coronary artery disease, renal insufficiency, and osteoporosis (Table 1). While osteoporosis was more prevalent among older patients, younger patients were more likely to suffer from urolithiasis. The proportion of patients with presence of an end-organ sequelae associated with pHPT (osteoporosis, renal insufficiency, or urolithiasis) showed a rise with age from $9.3 \%$ in the youngest group to $31.6 \%$ in the oldest subgroup.

\section{Incidence of in-hospital \\ postoperative complications}

The overall incidence of in-hospital postoperative complications was $4.2 \%$ (Table 2 ). While in patients below
50 years the incidence of postoperative complications was $4.6 \%$, it was lower in patients between 50 and 64 years $(2.9 \%)$, and increased to $6.8 \%$ in patients $\geq 75$ years. However, when compared with the youngest reference subgroup, there was no significant increase in the crude and adjusted odds of postoperative complications in all older subgroups.

Incidence ratios of the single components of the primary composite outcome are summarized in Table 3. Surgical re-interventions were more frequent in older patients. Postoperative hypocalcemia was the most frequent complication among the youngest subgroup.

\section{Secondary outcomes}

In-hospital mortality was low in the entire population $(n=1)$. The overall ICU-admission rate was $2.2 \%$, ranging from $1.9 \%$ in patients $<50$ years to $3.6 \%$ in the oldest subgroup. Before and after adjustment for covariates, there were no significant differences in ICU-admission between the reference group and the older ones.

We identified 71 (2.7\% of total cohort) unplanned allcause 30-day-readmissions, lowest in the reference group (1.9\%) and highest in patients $\geq 75$ years (4.8\%). However, multivariable logistic regression analysis revealed no significant differences in unplanned 30-day-readmission

Table 1 Baseline characteristics of the four age-groups.

\begin{tabular}{l}
\hline \\
\hline$N$ \\
Demographics, $n$ (\%) \\
Female gender \\
Swiss resident \\
Public insurance \\
Admission data, $n$ (\%) \\
Emergency admission \\
Tertiary hospital \\
Comorbidities, $n$ (\%) \\
Diabetes mellitus \\
Congestive heart failure \\
Cerebrovascular diseases \\
High blood pressure \\
Cancer \\
Coronary artery disease \\
Renal insufficiency \\
COPD \\
CCl, mean (s.D.) \\
Specific comorbidities, $n$ (\%) \\
Symptomatic HPT \\
Osteoporosis \\
Urolithiasis \\
Vitamine D deficiency \\
\end{tabular}

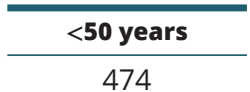

$319(67.3 \%)$
$319(67.3 \%)$
$389(82.1 \%)$

$0.18)$

$$
12(2.5 \%)
$$$$
431(90.9 \%)
$$

$13(2.7 \%)$

$2(0.4 \%)$

$0(0.0 \%)$

$53(11.2 \%)$

$0(0.0 \%)$

$2(0.4 \%)$

$9(1.9 \%)$

$2(0.4 \%)$

$0.10(0.58)$

$44(9.3 \%)$

$32(6.8 \%)$

$6(1.3 \%)$

$42(8.9 \%)$

\begin{tabular}{c}
\hline $\mathbf{5 0 - 6 4}$ years \\
\hline 1012 \\
$758(74.9 \%)$ \\
$833(82.3 \%)$ \\
$698(69.0 \%)$
\end{tabular}

$21(2.1 \%)$

$862(85.2 \%)$

$72(7.1 \%)$
$22(2.2 \%)$
$7(0.7 \%)$
$264(26.1 \%)$
$13(1.3 \%)$
$19(1.9 \%)$
$33(3.3 \%)$
$19(1.9 \%)$
$0.23(0.66)$

$203(20.1 \%)$

$167(16.5 \%)$

$7(0.7 \%)$

$72(7.1 \%)$

\begin{tabular}{c}
\hline $\mathbf{6 5 - 7 4}$ years \\
\hline 716 \\
$527(73.6 \%)$ \\
$630(88.0 \%)$ \\
$408(57.0 \%)$
\end{tabular}

\begin{tabular}{c}
\hline$\geq \mathbf{7 5}$ years \\
\hline 440 \\
$332(75.5 \%)$ \\
$393(89.3 \%)$ \\
$266(60.5 \%)$
\end{tabular}

\begin{tabular}{r}
\hline P-value \\
\hline \\
\\
0.011 \\
$<0.001$ \\
$<0.001$
\end{tabular}

$16(2.2 \%)$

$613(85.6 \%)$

$80(11.2 \%)$
$31(4.3 \%)$
$7(1.0 \%)$
$287(40.1 \%)$
$9(1.3 \%)$
$36(5.0 \%)$
$44(6.1 \%)$
$16(2.2 \%)$
$.39(0.93)$

179 (25.0\%)

$140(19.6 \%)$

$4(0.6 \%)$

$46(6.4 \%)$
$<0.001$

0.019

$<0.001$

$<0.001$

0.18

$<0.001$

0.056

$<0.001$

$<0.001$

0.1

$<0.001$

$<0.001$

$<0.001$

0.44

0.2

$\mathrm{CCl}$, Charlson comorbidity Index; COPD, chronic obstructive pulmonary disease; HPT, hyperparathyroidism.

https://ec.bioscientifica.com

https://doi.org/10.1530/EC-21-0363 (c) 2021 The authors Published by Bioscientifica Ltd

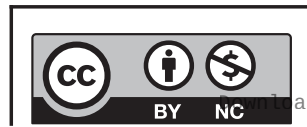

This work is licensed under a Creative Commons Attribution-NonCommercial 4.0 International License. ded from Bioscientifica.com at 04/26/2023 09:40:56AM via free access 
Table 2 Unadjusted and adjusted outcomes in different age-groups.

\begin{tabular}{l}
\hline Age in years \\
\hline Number of patients \\
In-hospital postoperative \\
complications \\
Total events (\%) \\
unadj. analysis, OR $(95 \% \mathrm{Cl}), P$-value \\
adj. analysisa, OR $(95 \% \mathrm{Cl}), P$-value \\
ICU admissions \\
Total events (\%) \\
unadj. analysis, OR $(95 \% \mathrm{Cl}), P$-value \\
adj. analysisa, OR $(95 \% \mathrm{Cl}), P$-value \\
Unplanned all-cause $30-\mathrm{day}$ - \\
readmissions \\
Total events (\%) \\
unadj. analysis, OR $(95 \% \mathrm{Cl}), P$-value \\
adj. analysisa, OR $(95 \% \mathrm{Cl}), P$-value \\
Length of hospital stay $>3$ days \\
Total events $(\%)$ \\
unadj. analysis, OR $(95 \% \mathrm{Cl}), P$-value \\
adj. analysisa, OR $(95 \% \mathrm{Cl}), P$-value \\
\hline
\end{tabular}

\begin{tabular}{c}
\hline $\mathbf{5 0}$ \\
\hline 474 \\
22 (4.6) \\
Ref. \\
Ref. \\
9 (1.9) \\
Ref. \\
Ref. \\
\\
9 (1.9) \\
Ref. \\
Ref. \\
50 (10.6) \\
Ref. \\
Ref. \\
\hline
\end{tabular}

\begin{tabular}{c}
\hline $\mathbf{5 0 - 6 4}$ \\
\hline 1012
\end{tabular}

\begin{tabular}{c}
\hline $\mathbf{6 5 - 7 4}$ \\
\hline 716
\end{tabular}

\begin{tabular}{l}
\hline$\geq 75$ \\
\hline 440
\end{tabular}

${ }^{a}$ Adjusted for gender, nationality, insurance status, date and type of admission, hospital size and teaching level, comorbidities, Charlson Comorbidity Index, Vitamin D deficiency and the presence of an end organ sequelae associated with primary hyperparathyroidism (osteoporosis, urolithiasis and/or renal insufficiency).

adj., adjusted; OR, odds ratio; Ref., reference; unadj., unadjusted.

between any older age group and the reference group. Reasonsfor unplanned readmission after parathyroidectomy are summarized in the Supplementary Table 1 (see section on supplementary materials given at the end of this article).

The overall mean LOS was 2.9 days. While only about $10 \%$ of the youngest patients were hospitalized $>3$ days, this was the case in about $28 \%$ in patients $\geq 75$ years. While we observed a comparable risk in patients below 75 years, in patients $\geq 75$ years the adjusted odds for a prolonged LOS of $>3$ days were 2.38 (95\% CI, 1.57 to 3.60) (Table 2).

\section{Sensitivity analysis}

We performed sensitivity analyses investigating potential effect modification of our results through the presence of a symptomatic pHPT (Fig. 2). In general, we found no significant interaction expect for prolonged LOS (Fig. 2D). Though, patients at age between 50 and 64 years were less likely to be hospitalized for $>3$ days if they were symptomatic as compared with those being asymptomatic $(P$ for interaction $=0.044)$.

\section{Discussion}

This population-based cohort study of more than 2500 patients with pHPT undergoing parathyroidectomy reveals two key findings: First, parathyroidectomy is safe, with remarkably low risks of in-hospital postoperative complications, ICU-admission, and unplanned

Table 3 Incidence of the single components of the composite endpoint 'in-hospital postoperative complications' in total cohort and different age-groups. A single patient may have more than one complication.

\begin{tabular}{|c|c|}
\hline Age in years & Total cohort \\
\hline$N$ & 2642 \\
\hline In-hospital postoperative complications, $n(\%)$ & $111(4.2)$ \\
\hline Surgical re-intervention, $n(\%)$ & $45(1.7)$ \\
\hline Hypocalcemia, $n(\%)$ & $23(0.9)$ \\
\hline Vocal cord paresis/recurrent nerve paresis, $n(\%)$ & $20(0.8)$ \\
\hline Bleeding and neck hematoma, $n(\%)$ & $17(0.6)$ \\
\hline Sepsis, $n(\%)$ & $5(0.2)$ \\
\hline Hemorrhagic shock/acute bleeding anemia, $n(\%)$ & $4(0.2)$ \\
\hline Tracheal or airways injury, $n(\%)$ & $4(0.2)$ \\
\hline Postoperative infection, $n(\%)$ & $2(0.1)$ \\
\hline Other postoperative complications, $n(\%)$ & $20(0.8)$ \\
\hline
\end{tabular}

\begin{tabular}{c}
\hline$<\mathbf{5 0}$ \\
\hline 474 \\
$22(4.6)$ \\
$6(1.3)$ \\
$10(2.1)$ \\
$3(0.6)$ \\
0 \\
$1(0.2)$ \\
0 \\
0 \\
0 \\
$3(0.6)$
\end{tabular}

\begin{tabular}{c}
\hline $\mathbf{5 0 - 6 4}$ \\
\hline 1012 \\
$29(2.9)$ \\
$12(1.2)$ \\
$7(0.7)$ \\
$1(0.1)$ \\
$8(0.8)$ \\
$2(0.2)$ \\
0 \\
$2(0.2)$ \\
0 \\
$7(0.7)$
\end{tabular}

\begin{tabular}{c}
\hline $\mathbf{6 5 - 7 4}$ \\
\hline 716 \\
$30(4.2)$ \\
$15(2.1)$ \\
$5(0.7)$ \\
$9(1.3)$ \\
$4(0.6)$ \\
$1(0.1)$ \\
$1(0.1)$ \\
$1(0.1)$ \\
$1(0.1)$ \\
$4(0.6)$
\end{tabular}

\begin{tabular}{c}
\hline$\geq \mathbf{7 5}$ \\
\hline 440 \\
$30(6.8)$ \\
$12(2.7)$ \\
$1(0.2)$ \\
$7(1.6)$ \\
$5(1.1)$ \\
$1(0.2)$ \\
$3(0.7)$ \\
$1(0.2)$ \\
$1(0.2)$ \\
$6(1.4)$ \\
\hline
\end{tabular}


A In-hospital postoperative complications

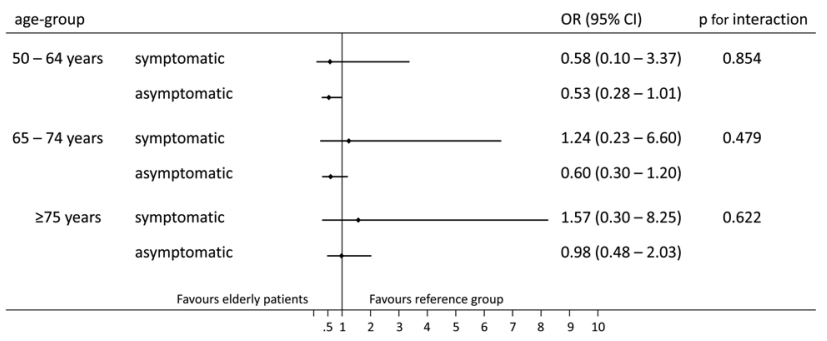

C Unplanned all-cause 30-day-readmission

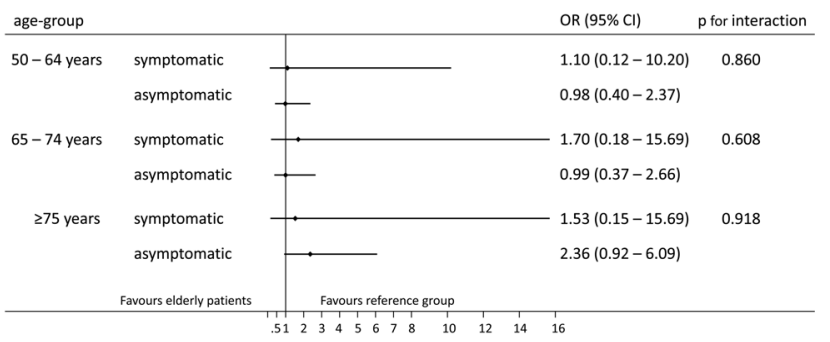

B ICU-admission

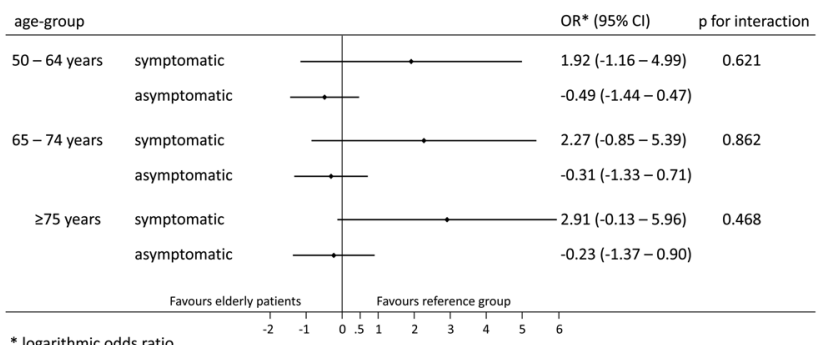

* logarithmic odds ratio

\section{Los > 3 days}

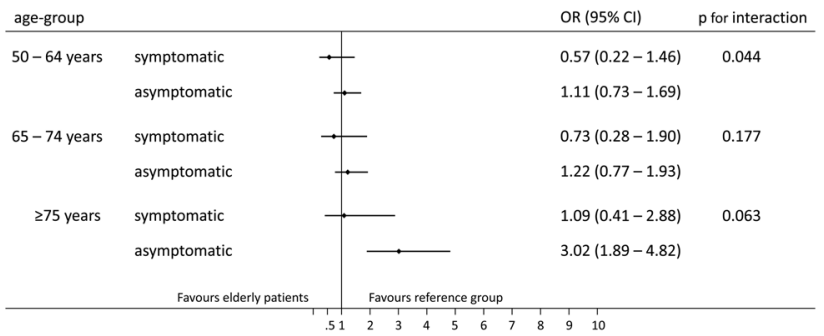

Figure 2

Sensitivity analysis stratified by the presence of a symptomatic primary hyperparathyroidism for primary and secondary outcomes (symptomatic defined as osteoporosis and/or renal insufficiency and/or urolithiasis). LOS, length of hospital stay; OR, odds ratio.

all-cause 30-day-readmission. Second, there were no significant differences in main clinical outcomes after parathyroidectomy among different age-groups, indicating that parathyroidectomy is safe even in older patients $\geq 75$ years.

There is an increase in evidence-based literature of parathyroidectomies and related patient outcomes.

While consensus guidelines focus on surgery in younger patients with $\mathrm{pHPT}$, only few efforts have been made to assess surgical outcomes in the older population suffering from pHPT (28). Today, parathyroidectomy is a definitive and mostly curative intervention with low morbidity and mortality risk. Medical but also technological advances in localizing the adenoma and fine-tuning surgical technique were followed by the deployment of evidencebased guidelines to define recommendations, stratify risk, personalize care, improve outcomes, reduce health care costs, and identify scientific argumentation for future efforts.

Consistent with our study, different previous analyses found similar results concerning postsurgical safety among older PTX-patients: a recent 'National Surgical Quality Improvement Program Study' found no difference in postsurgical complications between patients $>80$ years and those $<60$ years (25). Similarly, another study reported comparable complication rates for $\geq 65$ year old patients undergoing parathyroidectomy when compared to younger ones (21). A more previous study also underlines our findings by reporting similar rates for surgical re-explorations and postoperative complications between $<70$-year-old patients and patients $\geq 70$ years (19). In general, several studies have addressed the role of parathyroidectomy in older patients with pHPT and reported high levels of safety $(17,18,20,23,29)$.

However, there are a few conflicting results to be discussed. One study found increased 'overall and respiratory complications' in $\geq 65$-year-old patients with pHPT undergoing parathyroidectomy. Worth to note, in contrast to our study, the analysis by Thomas et al. included surgical re-explorations, but also non-surgical complications such as urinary tract infections and respiratory complications. However, they did not consider well-known complications such as laryngeal nerve injury and hypocalcemia, thus limiting comparability (22). In 2018, another study reported a higher risk of complications in frail and oldest patients $>75$ years (24). But again, as they also investigated non-surgical complications, comparability might be hindered.

In summary, as the term of 'postoperative or surgical complications' differs widely among previous investigations, its comparability is difficult to assess and requires specific definition of patient outcomes. In addition, the majority of studies comparing complications related to parathyroidectomy has been limited to their
This work is licensed under a Creative Commons Attribution-NonCommercial 4.0 International License. ded from Bioscientifica.com at 04/26/2023 09:40:56AM via free access 
distinctive study design and sample size (e.g. single surgeon reports, heterogeneity of included procedures/diagnoses) $(16,20,23,30)$. As we analyzed a large nationwide cohort of patients with pHPT solely, including patients from a wide range of different hospitals and surgeons, this study is likely to mirror a more accurate estimate at a national level.

Data on ICU-admission following parathyroidectomy in patients with pHPT are largely missing. ICU-admission was low in our cohort, emphasizing a high safety of PTX in Switzerland. In particular, we found no significant difference in ICU-admission between older patients and those $<50$ years. Nevertheless, one study reported increased rates of respiratory complications after parathyroidectomy in $\geq 65$-year-old patients, while considering intubation, ventilator-dependency, pneumonia, and pulmonary embolism (22).

In line with earlier studies, we did not see an increased risk of unplanned 30-day-readmission among older patients with pHPT $(30,31)$. Only one study found opposing results (32), which might be explained by a higher proportion of older patients with secondary HPT, again highlighting the heterogeneity of previous study populations and designs.

While hypocalcemia was the most frequent cause for a parathyroidectomy-related 30-day-readmission, we did not see any age-related differences among the subgroups $(30,31,32,33)$.

Compared to other countries LOS was longer in this study, therefore limiting its comparability due to a lower frequency of 'same-day parathyroidectomies' in Switzerland, largely for financial reasons of hospital reimbursement (https://www.swissdrg.org/de/ akutsomatik/swissdrg, accessed 16 July 2020). Nonetheless, most recent studies are consistent by reporting extended LOS or less frequent 'same-day surgeries' in older patients $(19,20,21,22,29)$.

Our retrospective, non-experimental study has limitations. First, analyzing administrative data is prone to confounding and the use of ICD-codes and CHOP-codes shows a risk of misclassification and underreporting. Thus, statistical underpower due to underreported complications cannot be excluded. In addition, as the current coding system in Switzerland does not provide more detailed information about the procedure of parathyroidectomy per se, we were not able to assess whether the surgical procedure encompassed a focused unilocular or even a multilocular exploration. Due to limited information on the type of primary hyperparathyroidism given by the claims database, we were not able to stratify for a single or multiple gland disease.
Second, as data on clinical and laboratory parameters was unavailable, we were not able to account for unmeasured/unmeasurable residual confounding. Third, the database was limited to in-hospital data. Apart from hospital-readmission, potential complications after discharge could not be tracked. As postsurgical hypocalcemia might be transient in the context of a 'hungry bone' phenomenon, a certain misclassification of postsurgical complications may be possible. Finally, confounding by indication is known to be relevant in populations undergoing surgical treatment, since patients with a higher rate of frailty are often not offered a surgical option.

\section{Conclusion}

In this nation-wide cohort study of patients with pHPT undergoing parathyroidectomy, rates of postoperative complications and other relevant clinical outcomes were comparable among different age subgroups. Against this background, parathyroidectomy should also be considered among older patients with an insufficiently controlled pHPT, in whom pharmacologic treatment is still preferred by most treating physicians.

\section{Supplementary materials}

This is linked to the online version of the paper at https://doi.org/10.1530/ EC-21-0363.

\section{Declaration of interest}

The authors declare that there is no conflict of interest that could be perceived as prejudicing the impartiality of the research reported.

\section{Funding}

This work was supported in part by the Swiss National Science Foundation (SNSF, National Research Program, NRP 74, 407440_167376), the research council (Grant 3071410.000.086) and the 'Wissenschaft \& Weiterbildung' (W\&W) Fonds (140.000.495) of the Kantonsspital Aarau AG, and the 'Hugo und Elsa Isner Foundation' of the Argovian Department of Health and Social Affairs and Funds from the 'Argovia Professur' of the Medical Faculty of the University of Basel. The funding sources had no role in design and conduct of the study; collection, management, analysis, and interpretation of the data; preparation, review, or approval of the manuscript; and decision to submit the manuscript for publication.

\section{Author contribution statement}

$\mathrm{M} \mathrm{M}$ and $\mathrm{A} \mathrm{K}$ designed the study and wrote the manuscript. A $\mathrm{K}$ had full access to all the data. $\mathrm{M} \mathrm{M}$ and $\mathrm{A} \mathrm{K}$ analyzed the data. All authors were responsible for the decision to submit the manuscript. All authors provided substantial comments on drafts and approved the final report.

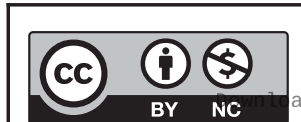

This work is licensed under a Creative Commons Attribution-NonCommercial 4.0 International License. ded from Bioscientifica.com at 04/26/2023 09:40:56AM 


\section{Statement of ethics}

This study complies with the guidelines for human studies and should include evidence that the research was conducted ethically in accordance with the World Medical Association Declaration of Helsinki.

\section{Acknowledgments}

We thank the Swiss Federal Office for Statistics (Bundesamt für Statistik, Neuchâtel, Switzerland) for the acquisition and provision of data.

\section{References}

1 Yu N, Donnan PT, Murphy MJ \& Leese GP. Epidemiology of primary hyperparathyroidism in Tayside, Scotland, UK. Clinical Endocrinology 200971 485-493. (https://doi.org/10.1111/j.1365-2265.2008.03520.x)

2 Yeh MW, Ituarte PH, Zhou HC, Nishimoto S, Liu IL, Harari A, Haigh PI \& Adams AL. Incidence and prevalence of primary hyperparathyroidism in a racially mixed population. Journal of Clinical Endocrinology and Metabolism 201398 1122-1129. (https://doi org/10.1210/jc.2012-4022)

3 Abood A \& Vestergaard P. Increasing incidence of primary hyperparathyroidism in Denmark. Danish Medical Journal 201360 A4567.

4 Miller BS, Dimick J, Wainess R \& Burney RE. Age- and sex-related incidence of surgically treated primary hyperparathyroidism. World Journal of Surgery 200832 795-799. (https://doi.org/10.1007/s00268007-9427-2)

5 Griebeler ML, Kearns AE, Ryu E, Hathcock MA, Melton 3rd LJ \& Wermers RA. Secular trends in the incidence of primary hyperparathyroidism over five decades (1965-2010). Bone 201573 1-7. (https://doi.org/10.1016/j.bone.2014.12.003)

6 Sywak MS, Robinson BG, Clifton-Bligh P, Reeve TS, Barraclough BH, Fick GH \& Delbridge LW. Increase in presentations and procedure rates for hyperparathyroidism in Northern Sydney and New South Wales. Medical Journal of Australia 2002177 246-249. (https://doi. org/10.5694/j.1326-5377.2002.tb04756.x)

7 Wu B, Haigh PI, Hwang R, Ituarte PH, Liu IL, Hahn TJ \& Yeh MW. Underutilization of parathyroidectomy in elderly patients with primary hyperparathyroidism. Journal of Clinical Endocrinology and Metabolism 201095 4324-4330. (https://doi.org/10.1210/jc.2009-2819)

8 Khan AA, Hanley DA, Rizzoli R, Bollerslev J, Young JE, Rejnmark L, Thakker R, D'Amour P, Paul T, Van Uum S, et al. Primary hyperparathyroidism: review and recommendations on evaluation, diagnosis, and management. A Canadian and International Consensus. Osteoporosis International 201728 1-19. (https://doi. org/10.1007/s00198-016-3716-2)

9 Berger C, Almohareb O, Langsetmo L, Hanley DA, Kovacs CS, Josse RG, Adachi JD, Prior JC, Towheed T, Davison KS, et al. Characteristics of hyperparathyroid states in the Canadian Multicentre Osteoporosis Study (CaMos) and relationship to skeletal markers. Clinical Endocrinology 201582 359-368. (https://doi.org/10.1111/cen.12569)

10 Walker MD \& Silverberg SJ. Primary hyperparathyroidism. Nature Reviews: Endocrinology 201814 115-125. (https://doi.org/10.1038/ nrendo.2017.104)

11 Bilezikian JP, Brandi ML, Eastell R, Silverberg SJ, Udelsman R, Marcocci C \& Potts JT, Jr. Guidelines for the management of asymptomatic primary hyperparathyroidism: summary statement from the Fourth International Workshop. Journal of Clinical Endocrinology and Metabolism 201499 3561-3569. (https://doi. org/10.1210/jc.2014-1413)

12 Zanocco KA, Wu JX \& Yeh MW. Parathyroidectomy for asymptomatic primary hyperparathyroidism: a revised cost-effectiveness analysis incorporating fracture risk reduction. Surgery 2017161 16-24. (https:// doi.org/10.1016/j.surg.2016.06.062)
13 Peacock M, Bolognese MA, Borofsky M, Scumpia S, Sterling LR, Cheng S \& Shoback D. Cinacalcet treatment of primary hyperparathyroidism: biochemical and bone densitometric outcomes in a five-year study. Journal of Clinical Endocrinology and Metabolism 200994 4860-4867. (https://doi.org/10.1210/jc.2009-1472)

14 Shoback DM, Bilezikian JP, Turner SA, McCary LC, Guo MD \& Peacock M. The calcimimetic Cinacalcet normalizes serum calcium in subjects with primary hyperparathyroidism. Journal of Clinical Endocrinology and Metabolism 200388 5644-5649. (https://doi. org/10.1210/jc.2002-021597)

15 Wilhelm SM, Wang TS, Ruan DT, Lee JA, Asa SL, Duh QY, Doherty GM, Herrera MF, Pasieka JL, Perrier ND, et al. The American Association of Endocrine Surgeons Guidelines for definitive management of primary hyperparathyroidism. JAMA Surgery 2016151 959-968. (https://doi. org/10.1001/jamasurg.2016.2310)

16 Chen H, Parkerson S \& Udelsman R. Parathyroidectomy in the elderly: do the benefits outweigh the risks? World Journal of Surgery 199822 531-535; discussion 535-536. (https://doi.org/10.1007/ s002689900431)

17 Irvin GL, 3rd \& Carneiro DM. 'Limited' parathyroidectomy in geriatric patients. Annals of Surgery 2001233 612-616. (https://doi. org/10.1097/00000658-200105000-00003)

18 Kebebew E, Duh QY \& Clark OH. Parathyroidectomy for primary hyperparathyroidism in octogenarians and nonagenarians: a plea for early surgical referral. Archives of Surgery 2003138 867-871. (https:// doi.org/10.1001/archsurg.138.8.867)

19 Bachar G, Gilat H, Mizrachi A, Shimon I, Feinmesser R, Kaizerman I \& Shpitzer T. Comparison of perioperative management and outcome of parathyroidectomy between older and younger patients. Head and Neck 200830 1415-1421. (https://doi.org/10.1002/hed.20887)

20 Stechman MJ, Weisters M, Gleeson FV, Sadler GP \& Mihai R. Parathyroidectomy is safe and improves symptoms in elderly patients with primary hyperparathyroidism (PHPT). Clinical Endocrinology 200971 787-791. (https://doi.org/10.1111/j.1365-2265.2009.03540.x)

21 Young VN, Osborne KM, Fleming MM, Flynn MB, Goldstein RE \& Bumpous JM. Parathyroidectomy in the elderly population: does age really matter? Laryngoscope 2010120 247-252. (https://doi. org/10.1002/lary.20706)

22 Thomas DC, Roman SA \& Sosa JA. Parathyroidectomy in the elderly: analysis of 7313 patients. Journal of Surgical Research 2011170 240-246. (https://doi.org/10.1016/j.jss.2011.03.014)

23 Calo PG, Medas F, Loi G, Pisano G, Sorrenti S, Erdas E \& Nicolosi A. Parathyroidectomy for primary hyperparathyroidism in the elderly: experience of a single endocrine surgery center. Aging Clinical and Experimental Research 201729 (Supplement 1) 15-21. (https://doi. org/10.1007/s40520-016-0666-7)

24 Seib CD, Chomsky-Higgins K, Gosnell JE, Shen WT, Suh I, Duh QY \& Finlayson E. Patient frailty should be used to individualize treatment decisions in primary hyperparathyroidism. World Journal of Surgery 201842 3215-3222. (https://doi.org/10.1007/s00268-018-4629-3)

25 Khokar AM, Kuchta KM, Moo-Young TA, Winchester DJ \& Prinz RA. Parathyroidectomy is safe in elderly patients: a National Surgical Quality Improvement Program Study. World Journal of Surgery 202044 526-536. (https://doi.org/10.1007/s00268-019-05280-9)

26 Aharonson-Daniel L, Boyko V, Ziv A, Avitzour M \& Peleg K. A new approach to the analysis of multiple injuries using data from a national trauma registry. Injury Prevention 20039 156-162. (https:// doi.org/10.1136/ip.9.2.156)

27 von Elm E, Altman DG, Egger M, Pocock SJ, Gotzsche PC, Vandenbroucke JP \& STROBE Initiative. The Strengthening the Reporting of Observational Studies in Epidemiology (STROBE) statement: guidelines for reporting observational studies. International Journal of Surgery 201412 1495-1499. (https://doi.org/10.1016/j. ijsu.2014.07.013)

28 Kuo EJ, Al-Alusi MA, Du L, Shieh A, Livhits MJ, Leung AM \& Yeh MW. Surgery for primary hyperparathyroidism: adherence to consensus

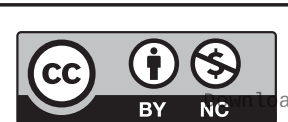

This work is licensed under a Creative Commons Attribution-NonCommercial 4.0 International License. ded from Bioscientifica com at 04/26/2023 09:40:56Am 
guidelines in an academic health system. Annals of Surgery 2019269 158-162. (https://doi.org/10.1097/SLA.0000000000002474)

29 Grogan RH, Mitmaker EJ, Hwang J, Gosnell JE, Duh QY, Clark OH \& Shen WT. A population-based prospective cohort study of complications after thyroidectomy in the elderly. Journal of Clinical Endocrinology and Metabolism 201297 1645-1653. (https://doi.org/10.1210/jc.2011-1162)

30 FitzGerald RA, Sehgal AR, Nichols JA \& McHenry CR. Factors predictive of emergency department visits and hospitalization following thyroidectomy and parathyroidectomy. Annals of Surgical Oncology 201522 (Supplement 3) S707-S713. (https://doi.org/10.1245/ s10434-015-4797-4)

31 Kravietz AM, Buicko JL, Parreco JP, Lopez MA \& Kozol RA. Thirtyday readmissions following parathyroidectomy: evidence from the National Readmissions Database, 2013-2014. American Journal of Otolaryngology 201839 82-87. (https://doi.org/10.1016/j. amjoto.2018.01.006)

32 Roche AM, Brant JA \& Chai RL. Predictors of readmission and reoperation in patients undergoing parathyroidectomy for primary hyperparathyroidism. Otolaryngology: Head and Neck Surgery 2018158 828-834. (https://doi.org/10.1177/0194599818758019)

33 Singh Ospina NM, Rodriguez-Gutierrez R, Maraka S, Espinosa de Ycaza AE, Jasim S, Castaneda-Guarderas A, Gionfriddo MR, Al Nofal A, Brito JP, Erwin P, et al. Outcomes of parathyroidectomy in patients with primary hyperparathyroidism: a systematic review and metaanalysis. World Journal of Surgery 201640 2359-2377. (https://doi. org/10.1007/s00268-016-3514-1)

Received in final form 2 September 2021

Accepted 13 September 2021

Accepted Manuscript published online 14 September 2021
This work is licensed under a Creative Commons Attribution-NonCommercial 4.0 International License.

ded from Bioscientifica.com at 04/26/2023 09:40:56AM 